\title{
ПЕТР ЧААДАЕВ КАК УЧРЕДИТЕЛЬНЫЙ МИФ РУССКОЙ ФИЛОСОФИИ
}

\begin{abstract}
Януш Добешевский
Профессор,

преподаватель Института философии Варшавского университета; специализируется на истории философии, социальной философии, философии религии, русской философии.

E-mail: dobieszewski@uw.edu.pl
\end{abstract}

$\prod \begin{aligned} & \text { онятие учредительного мифа (aitiología) касается генезиса и источников } \\ & \text { существенных событий и явлений в истории культуры, цивилизации и }\end{aligned}$ общественной жизни, о которых помнят до сих пор или которые, по крайней мере, не перестают приковывать к себе внимание историков. Но этот термин используется и для описания сегодняшних ситуаций, происходящих почти на наших глазах, если им хотят придать важность и глубину, указав на их истоки. В истории русской философии лишь Чаадаев выглядит в этой роли максимально эффектно и убедительно. В статье рассматриваются параметры, доказывающие это положение.

Ключевые слова: П. Я. Чаадаев, учредительный миф, «Философические письма», западничество, славянофильство.

DOI 10.17323/2658-5413-2019-2-4-90-103

$\mathrm{Y}$ чредительный миф - понятие, относящееся в первую очередь к отдаленным истокам человеческой культуры. Оно касается генезиса и источников существенных событий и явлений в истории культуры, цивилизации и общественной жизни, о которых помнят до сих пор или которые по крайней мере не перестают приковывать к себе внимание историков. Но этот термин используется и для описания сегодняшних ситуаций, происходящих почти на наших глазах, если им хотят придать важность и глубину, указав на их истоки. С помощью учредительного мифа и благодаря ему мы хотим перейти к самому началу, зарождению некоего важного явления и описать его ключевые черты, имеющие непреходящую символическую значимость. Ведь мы убеждены, что на начальном этапе проявили себя самые важные особенности явления, навсегда его сформировавшие, что в отправной точке оно выразилось во всей чистоте, подлинности, спонтанности, с уникальной энергией и жизненной силой. Позже это явление окажется под влиянием осложняющих и искажающих изме- 
нений, внутренних перемен и внешних воздействий, которые в значительной степени затемнят его суть, а значит, исследователь будет вынужден вернуться к истокам.

Учредительные мифы характерны, конечно, для религии - и религии с необыкновенным вниманием и тщательностью пестуют свои учредительные мифы как свое центральное и вечно живое обоснование, - но могут относиться и к государствам, общественным и политическим движениям и даже научным дисциплинам. Например, учредительный миф христианства - это богочеловечество Иисуса Христа, буддизма - пробуждение и просветление Сиддхартхи Гаутамы, ислама - пророческая жизнь Мухаммеда; учредительный миф российского государства - призвание варягов, Французской республики - взятие Бастилии, Советского Союза - выстрелы «Авроры», социалистической Польши - Манифест 22 июля, современной Польши - Круглый стол; учредительный миф физики - яблоко Ньютона или даже ванна Архимеда, медицинского искусства - клятва Гиппократа.

Учредительные мифы обращаются к ситуациям легендарным и даже сказочным, которые, конечно, не могут быть убедительно подтверждены, но очаровывают, покоряют воображение, расширяют возможности интерпретации. Также они соотносятся и с реальными фактами, явно имевшими место, хотя чаще всего являются в значительной степени неоднозначными, оставаясь объектами споров, относятся к персонажам и событиям, постоянно возбуждающим вопросы и сомнения, которые не могут быть окончательно разрешены. Необходимо, чтобы учредительный миф сопровождала атмосфера тайны; человека или людей, выступающих в мифе, окружает некая аура необычности, уникальности, им свойственна харизма. Учредительный миф является поворотным событием, это реприза, завершающая существовавший дотоле мир, но прежде всего вторжение нового, иного мира, приводящее к тому, что в некоей области «все только начинается»; это момент вмешательства более близкого (горизонтального) или более далекого (вертикального), но всегда трансценденции по отношению к текущему ходу вещей. Герои мифа видятся отмеченными божественной, сверхъестественной миссией, которая делает их жизнь служением и вдохновенным усилием. Здесь легко начать драматизировать или представлять мифологическую ситуацию с привлекательных сторон, но неоднозначность учредительного мифа способствует, в свою очередь, инакомыслию, ересям, а также преобразованиям и отклонениям, что, однако, свидетельствует о живой силе мифа. Адепты и защитники - отнюдь не только хранители памяти; учредительный миф требует постоянной, систематической работы, внимания, бдительности. Он всегда существует под угрозой полного переосмысления или даже ликвидации. Мы писали выше о Круглом столе (политическое событие, 
которое приготовило конец социализма в Польше в 1989 г.) как учредительном мифе современной Польши - яркий пример того, как содержание, смысл мифа в определенный момент становится предметом страстных споров, ссор и мифологизированных контрпредложений.

Все эти рассуждения призваны создать фон для четкой, но при этом свободной от упрощения интерпретации повсеместно признанной особой роли Петра Чаадаева в истории русской философии. Определение творчества и хода жизни Чаадаева как учредительного мифа русской философии отражает уникальный характер его появления в истории России, но также сохраняет присущую ему ауру неоднозначности, тайны и даже чудачества.

Хотя начало русской философии усматривают порой в позднем Средневековье и древнерусской мысли; хотя иногда пытаются принять за отправную точку фигуру Григория Сковороды, мистика и моралиста, жившего в XVIII в.; хотя трудно не отметить пусть и подражательный, но довольно яркий интеллектуальный фермент эпохи Екатерины Великой; хотя, наконец, невозможно переоценить качество и количество трудов Владимира Соловьева, которого некоторые считают создателем русской философии, - лишь Чаадаев выглядит в этой роли максимально эффектно и убедительно. Его появление полностью соответствует формуле учредительного мифа. Ее невозможно связать с древнерусской мыслью, со Сковородой, с эпохой Просвещения, равно как и с Соловьевым - в последнем случае это было бы анахронизмом. Чаадаев - и только он - это, по словам Бердяева, «пробуждение самостоятельной, оригинальной русской мысли» (Ермичев (сост.), 467), по мнению Зеньковского, «целый ряд крупных мыслителей России возвращается к темам Чаадаева» (Там же: 494), «Чаадаев оказался пионером новых маршрутов русской мысли», - считал Иванов-Разумник (Там же: 399), «до него никто в России не говорил таким всемирным голосом» - это Мережковский (Там же: 415). Современный исследователь утверждает, что «его идеи оказали решающее влияние на состояние и развитие русской философии» (Евлампиев, 2000: 50). Знаменитой стала фраза Герцена из «Былого и дум» о первом философическом письме: «Это был выстрел, раздавшийся в темную ночь; тонуло ли что и возвещало свою гибель, был ли это сигнал, зов на помощь - весть об утре или о том, что его не будет - все равно надобно было проснуться» (Герцен, 2018: 100).

Самым важным и наиболее известным событием в жизни Чаадаева и России в связи с Чаадаевым была публикация в 1836 г. первого философического письма ${ }^{1}$. Она повлекла за собой крайне резкую реакцию властей: Чаадаев был объявлен сумасшедшим и взят под надзор врачей и полиции, отмененный год

\footnotetext{
${ }^{1}$ Всего было восемь «Философических писем», хотя к ним иногда присоединяют еще одно, девятое; публикация остальных писем произошла после смерти Чаадаева.
} 
спустя при условии, что он «не посмеет больше ничего писать» (Гершензон, 1908: 140). И Чаадаев действительно больше ничего уже не публиковал, однако оставил небольшое количество рукописей и вел интересную переписку. Собственно говоря, контекст его социальной жизни вплоть до смерти в 1856 г. и творчество (во многих случаях, впрочем, довольно хорошо известное современникам) придали событиям вокруг первого письма статус учредительного мифа.

Необычайно резкое решение властей в 1836 г. имело значительное влияние на дальнейшее развитие русской мысли и действительности, приведя к тому, что последующие властители с неизменным подозрением относились к теориям, которые основывались на концепции Чаадаева или развивали ее. А так как это относилось почти ко всем русским философским и социальным теориям, начиная со славянофильства и кончая марксизмом, то под подозрение попала философия и социальная мысль в целом; Чаадаев стал своего рода «первородным грехом» русской мысли, что в некоторой степени предвещает появление учредительного мифа, хотя и не является достаточным основанием.

Надо добавить, что эффектом и обратной стороной политизации мысли властями явилась политизация ее самими создателями, даже если их первоначальные намерения были от того далеки - своего рода проклятие политики. Если абстрактная, без прямых политических акцентов, теория Чаадаева считалась проявлением политически опасного безумия, это должно было поднять вопрос о характере реальности, в которой такая оценка имела место, а с другой стороны - о содержании мысли, вызывающей такие реакции. Вне зависимости от ответов это привело, во-первых, к чрезвычайно высокому политическому потенциалу русской философии и исключительно сильному присутствию в ней текущих вопросов общественной жизни, и, во-вторых, к высокой степени самосознания и самокритицизма русской мысли, к ее непрерывному саморазвитию через вопросы о себе, о своем месте в обществе, о пределах своей свободы.

По своему содержанию первое философическое письмо Чаадаева, к которому мы скоро вернемся, - это радикальный и жесткий анализ состояния России и ее места в истории. А никакого места у нее, собственно, нет, так как Россия принадлежит не истории, а лишь географии. Мы имеем дело с отсутствием развития, прогресса, какого-либо механизма для накопления опыта, формирования навыков. Здесь интеллектуальная жизнь все время возвращается к исходной точке, так как она не в состоянии усвоить и поддерживать новые идеи. «Мы живем, - пишет Чаадаев, - лишь в самом ограниченном настоящем без прошедшего и без будущего, среди плоского застоя. <...> не восприняли мы и традиционных идей человеческого рода» (Чаадаев, 1991а: 325). Россия в этой ситуации не смогла создать ничего, что вошло бы в сокровищницу человече- 
ских достижений и хотя бы немного ускорило развитие человечества, более того - она не создала ничего для себя. В результате, в жизни России «равнодушие к добру и злу, ко всякой истине, ко всякой лжи» (Там же: 328).

Именно эти высказывания вызвали враждебную реакцию властей (да и большей части общества), а с другой - привели, например, у Герцена, к изображению Чаадаева западником и радикальным критиком российских общественно-политических порядков. В этом ключе о Чаадаеве позднее писали Плеханов и связанный с кругом русской религиозной философии Михаил Гершензон, который утверждал по поводу решения властей после публикации первого письма, что «более циничной, насмешливой победы физической силы над умом, над словом, над человеческим достоинством мы не могли видеть даже в России» (Гершензон, 1908: 137). Такой образ Чаадаева сложился почти исключительно из-за содержания первого письма и, похоже, в значительной степени способствует продвижению мифа Чаадаева; однако это односторонняя перспектива. Она действительно увековечивает легенду о позорно преследуемом философе, чего, по нашему мнению, ни в коем случае недостаточно - именно в силу односторонности и слишком явной очевидности - для возникновения учредительного мифа. В этом контексте кажутся убедительными замечания польского исследователя, что по отношению к Чаадаеву «проскрипционные списки секретных служб императора не были обширными, а надзор врачей и полиции над басманным философом, равно как и ссылка Надеждина [издателя журнала “Телескоп”, который опубликовал первое письмо], которому было дозволено заниматься наукой, длились сравнительно недолго и не привели к актам мученичества. Более того, сам Чаадаев, подписывавший многие письма словом “Безумный”, подробно представляя состояние своего духа, как бы романтизирует “телескопную историю”» (Jedliński, 2015: 190). В свою очередь, Дмитрий Мережковский, рассуждая об умеренном личном мужестве Чаадаева, писал, что «он был мудрецом, а не мучеником» (Ермичев (сост.), 1998: 409).

Но самое главное для нашего дела - это содержание произведений Чаадаева. И в этом контексте представление о нем как западнике и радикальном социально-политическом мыслителе можно защитить - впрочем, не совсем убедительно - только в том случае, если мы выделим первое письмо из всего, хотя и не слишком обширного, интеллектуального творчества Чаадаева. И действительно, как мы уже писали, есть такие интерпретации, согласно которым Чаадаев выступает в двух ролях: он играет, по словам В. В. Кожинова, и «роль автора первого письма (трактуемого как абсолютный и убедительный “приговор” России), и роль личности, роль человека в его целостности» (Там же: 707) Но интерпретаторы выбирают обычно первую роль, сводя вклад Чаадаева в интеллектуальную историю России только к первому письму. Однако это карти- 
на односторонняя, поверхностная, сводящая философа к части его творчества, ограниченная захватывающей легендой первого письма за счет гораздо более глубокой и относящейся ко всей деятельности Чаадаева роли учредительного мифа русской философии. Концентрация на знаменитой легенде первого письма с неизбежностью ведет к дискредитирующей психологизации почти всего остального творчества Чаадаева, особенно якобы «пророссийской» и почти «предславянофильской» «Апологии сумасшедшего», написанной в 1837 г., которая, с этой точки зрения, является свидетельством трусости философа и ухода от проекта, содержащегося в первом «Философическом письме».

Между тем ни первое философическое письмо, ни, тем более, все письма в совокупности, не являются таким уж антироссийскими, равно как и «Апология» не настолько славянофильская, как кажется, если руководствоваться вышеприведенным поспешным стереотипом. В первом письме Чаадаев, восхваляя историческое развитие Европы, писал: «Я, конечно, не утверждаю, что среди нас одни только пороки, а среди народов Европы одни добродетели, избави Бог. Но я говорю, что для суждения о народах надо исследовать общий дух, составляющий их сущность, ибо только этот общий дух способен вознести их к более совершенному нравственному состоянию и направить к бесконечному развитию, а не та или другая черта их характера»; и далее: «разумеется, в странах Европы не все исполнено ума, добродетели, религии, совсем нет» (Чаадаев, 1991п: 329, 335). Первое письмо подытоживается мыслью, являющей образец благоразумия и компромисса: «<..> невзирая на все незаконченное, порочное и преступное в европейском обществе, как оно сейчас сложилось, все же царство Божие в известном смысле в нем действительно осуществлено, потому, что общество это содержит в себе начало бесконечного прогресса и обладает в зародыше и в элементах всем необходимым для его окончательного водворения в будущем на земле» (Там же: 336). Еще более усложняют этот вопрос следующие письма, а письмо VII заканчивается утверждением, которое представляет собой почти переход к «Апологии»: « <...> в наши дни силы высшего общества так возросли, его действие на остальную часть человеческого рода так расширилось, что вскоре мы будем увлечены всемирным вихрем, и телом и духом, это несомненно: нам никак не удастся долго еще пробыть в нашем одиночестве» (Там же: 433-434). С другой стороны, критицизм по отношению к Европе в «Апологии» - это не пересмотр оценки из Писем, а смена акцента, «сдвиг» сравнительно статичных понятий. Так что, признавая в «Апологии», что он, «может быть, слишком превознес» европейские страны в «Философических письмах», Чаадаев тут же добавляет: «тем не менее [они] являются наиболее полными образцами цивилизации во всех ее формах», которая одновременно «подавлена своими традициями и воспоминаниями», и требует возрождения 
со стороны тех, кто «хочет учиться» (а это русский народ), и кому «позволено надеяться на благоденствие еще более широкое, чем то, о котором мечтают самые пылкие служители прогресса» (Там же: 534, 535), но далеко не такое, как представляли славянофилы.

Итак, мы убеждены в целостности позиции Чаадаева, когда речь идет о русско-европейском вопросе, а бурную реакцию на «Апологию сумасшедшего» - якобы в ней отсутствует связь с благородной и героической честностью первого письма - склонны рассматривать как результат слишком быстрого и поверхностного взгляда. Идея исторической миссии России присутствует вопреки поверхностному взгляду - по крайней мере, в следующих философических письмах, и, следовательно, заявлена задолго до «Апологии»; «таким образом, вы должны отвергнуть понимание, - справедливо пишет польский исследователь, - что идеи “Апологии сумасшедшего” возникли в результате “тактических уступок мыслителя в отношении политической власти и оскорбленного общественного мнения"» (Przebinda, 1998: 104).

Объясняя таким образом отношения между «Философическими письмами» и «Апологией сумасшедшего», мы хотели бы выдвинуть, быть может, еще более важный тезис: Чаадаев - мыслитель, находящийся за рамками противопоставления «западничество-славянофильство», его философия предшествует этой оппозиции, закладывает ее основы. И именно этот тезис показывает, как жизнь и творчество Чаадаева приобретают характер учредительного мифа. Как западник или даже славянофил (хотя такую оценку можно встретить реже), Чаадаев получил бы звание творца, мастера, отца-основателя одного из этих направлений, особенно западничества, и находился бы в четко определенной роли на интеллектуальной карте России 1830-х - 1850х гг. Напротив, как мыслитель, предшествующий спору западников и славянофилов, Чаадаев становится учредительным мифом русской философии во всей ее целостности, общего и затем дифференцирующегося проблемного поля - первоначально спора славянофильства и западничества, а затем преобразовавшегося. При этом Чаадаев всегда остается тем, кто не принадлежит какому-то одному направлению, во всех случаях занимая позицию предшественника; его личность и деятельность становятся учредительным мифом, что не тождественно роли отца-основателя, авторитета или классика какого-либо направления русской философии.

Из сказанного следует, что мы понимаем учредительный миф как явление синтезирующее, суммирующее, обобщающее, основывающее и проблематизирующее некоторые возможности, заключения, уже являющиеся конкретными позициями в смысловом пространстве, созданном учредительным мифом. Проблематизация, как правило, принимает форму некоторого противопостав- 
ления, более или менее явно выраженного спора между противоположными позициями или проектами (в нашем случае это, как мы хорошо знаем, антитеза «славянофильство-западничество»), которые часто занимают собой почти все интеллектуально-культурное пространство, но при этом, бывает, переформулируются и переходят в новые формы противоположностей, не обязательно и не всегда дуалистическиих. Такой образ Чаадаева как мыслителя, предшествующего оппозиции «славянофильство-западничество» или поднимающегося над ней, мы без труда найдем в литературе, и нам кажется, что он адекватен с точки зрения как внутреннего содержания взглядов Чаадаева, так и его роли в истории русской философии.

Обозначенная здесь синтетичность, тотальность учредительного мифа особенно в контексте формирования на его основе противостоящих или даже бинарных мировоззренческих и интеллектуальных структур в русской мысли - придает ему уже упомянутую неоднозначность, амбивалентность, напряженность, нечто таинственное и загадочное, что оказывается выражением его целостности и влияет на глубину и широту проявляющегося здесь философского мышления, но иногда бывает утомительным вызовом для обыденного мышления и рассудочного подхода, охотно сводящих мысль Чаадаева к одной из сторон зафиксированных им оппозиций, а также психологизирующих ее или обвиняющих в легко выявляемых логических противоречиях и несогласованностях.

Эту крайне интересную синтетичность и сопровождающую ее двусмысленность, даже странность (а с точки зрения рассудка - противоречивость) мысли Чаадаева замечательно прокомментировал Анджей Валицкий: Чаадаев «сформулировал с особой силой ряд важных проблем, принятых позже людьми с диаметрально противоположными идеологическими ориентациями - западниками и славянофилами, Герценом и Достоевским, Чернышевским и Соловьевым. Он был западником, но духовно чуждым либеральной, буржуазной Европе, антиреволюционером, давшим интеллектуальный импульс революционерам; религиозным мыслителям, принимаемым антирелигиозной или нерелигиозной прогрессивной интеллигенцией, которая вслед за Герценом видела в нем воплощение протеста против гнетущей силы русского самодержавия» (Walicki, 2005: 150).

Мы хотели бы дальше развить и конкретизировать целостный, синтетический, мифологически-учредительный смысл мысли Чаадаева, в значительной степени заключающийся в присутствии противоположностей при определенном равновесии, единстве, некоем тотальном общении, из которого впоследствии выделятся оппозиции, приходящие к самостоятельности в различных формах русской философской и общественной мысли. 
Так, в христианстве Чаадаев находил для своего целостного, тотального, универсального видения мира наилучшую идейно-мировоззренческую форму. Христианство было и остается основой положительных ценностей и достижений Европы, из него возникают силы и энергии человеческой деятельности, и в то же время оно словно служит ее общим знаменателем, гарантией участия во всеобщей истории человечества. Именно через христианскую идею жизнь общества трансформировалась в преемственность фактов и идей, в долговечный, ничем не сдерживаемый прогресс. «Взгляните, - писал Чаадаев, - какое разнообразие свойств, какое множество сил она приводит в движение, сколько различных способностей сливает воедино, сколько несходных сердец заставляет биться из-за одной и той же идеи!» (Чаадаев, 1991a: 338). Но надлежащее понимание объединительной силы христианства заключается в выявлении и понимании двух его аспектов - не только мистического, но и социально-исторического: «Ничего не понимают в христианстве те, которые не замечают в его чисто исторической стороне, составляющей столь существенную часть вероучения, что в ней до некоторой степени заключается вся философия христианства, так как именно здесь обнаруживается, что оно сделало для людей и что ему предстоит сделать для них в будущем»; христианство есть сила «видимого действия» и влечет за собой «социальную идею» (Там же: 332, 334). Однако эти два аспекта христианства имеют тенденцию становиться независимыми друг от друга, тяготеют к партикуляризации, результатом чего стали католицизм с доминированием историко-социального аспекта и православие с доминированием аспекта догматически-мистического. Тенденция к односторонней реализации христианства показывает, что сохранение его единства требует заботы, внимания, активной деятельности, личного тщания; оно не дано и не обеспечено, не упадет с неба.

В пространстве русской философии две противоположные, хотя и вырастающие из одного источника направленности обрели течение в двух, может быть, наиболее общих (даже по сравнению со спором «славянофильство-западничество») руслах - критически-социальном и философско-религиозном. В обоих мышление Чаадаева стало общей основой. Они стремятся указать его основополагающим источником. Со стороны социальной философии известнейшую ссылку на Чаадаева как родоначальника мы обнаруживаем у Герцена, со стороны религиозной философии - в многочисленных заявлениях ее представителей, а в наиболее систематизированной форме - в монографии Гершензона «П. Я. Чаадаев. Жизнь и мышление». Отметим также, что объединительная сила мысли Чаадаева до некоторой степени действовала даже в принципиально односторонних или частичных продолжениях. Так, в русской социальной философии всегда присутствовал определенный аспект религиоз- 
ного имманентизма, что особенно подчеркивали Зеньковский и Бердяев, а русская религиозная философия, в свою очередь, всегда содержала чрезвычайно мощный историософский или общественно-политический аспект. Аналогичные целостные и синтетические мотивы мы находим, кстати, также в славянофильстве и в западничестве. По нашему мнению, это свидетельствует, что чаадаевский учредительный миф, касающийся образования русской философии, не только историчен и формален, но и актуален как всегда присутствующая тенденция, «настрой», который можно без особого труда обнаружить и в односторонних последствиях, вытекающих из учредительного мифа.

Другим проявлением синтетической, объединяющей природы мысли Чаадаева, которая позже расщепляется в различных продолжениях и расширениях, являются источники этой мысли. Указывается здесь, как правило, на французский католический традиционализм (де Бональд, де Местр, Ламенне) и германскую классическую философию, особенно в лице Гегеля и Шеллинга. Для нас в контексте дальнейшего развития русской философии второй источник особенно важен, поскольку содержит представление о всеобъемлющем единстве. В самом деле, русскую мысль часто представляют как оппозицию двух начал, вырастающих или из мистицизма, эстетизма, натурфилософии, положительной философии Шеллинга, или из историзма, имманентизма, рационализма и философии отрицания Гегеля. Чаще связывают Чаадаева с философией Шеллинга (с которой, кстати, связывают также славянофильство), но Чаадаев писал Шеллингу: «Я часто приходил в конце концов к совершенно иным результатам, чем вы» (Чаадаев, 19916: 75). Но, с другой стороны, социально-историческое понимание бытия, в особенности идея хитрости разума, похоже, подталкивают поместить Чаадаева в круг гегельянства (с которым, кстати, связывают и западничество). Потому представляется, что мысль Чаадаева некоторым образом вдохновлена философией и Шеллинга, и Гегеля, и по этому вопросу - родства с шеллингианством или гегельянством - можно прийти к каким-то более однозначным выводам лишь в позднейших течениях русской философии.

Предпринимая еще одну попытку осознать единство, цельность и синтетизм мысли Чаадаева, которая, впрочем, не всегда подлежит точной концептуализации и лишь позже, в концепциях, возникших после него и выросших под его влиянием, стала более четкой и в то же время запутанной из-за присутствия прямо противоположных позиций, мы указали бы на характерное для его мысли сосредоточение на единстве идеального и реального, на взаимное проникновение трансценденции и имманенции (и столь часто встречаемую в русской мысли, хотя и декларативно отрицаемую, пантеистическую угрозу), на связь данного и заданного (Там же: 75). 
Еще один косвенный аргумент в пользу единства и целостности мысли Чаадаева - в нашем понимании основа учредительного мифа, - что исследователи русской мысли видят Чаадаева отцом-основателем, вдохновителем почти всех основных направлений русской философии, в том числе тех, которые, кажется, противоречат друг другу. Мы уже отмечали, что Чаадаева называют создателем, или, по крайней мере, источником западничества (Герцен, Плеханов) и славянофильства (Чернышевский), но это касается также Соловьева и русской религиозной философии (Гершензон), попыток объединения христианства и либерализма (Зеньковский), Достоевского, идеи всечеловеческого инстинкта русских (Гершензон), народничества (Чернышевский, Гершензон; последний особо отмечает посредничество Герцена) и субъективизма (это связано с верой в возможность осознанного выбора Россией своего будущего - Плеханов), и, наконец, проекта нового религиозного сознания (Мережковский) и богостроительства (Плеханов ${ }^{1}$ ), и даже нигилизма и разумного эгоизма. Неудивительно, что встречается также наиболее убедительный в этом отношении взгляд о «внепартийности» Чаадаева, и неудивительно, что, хотя отпечаток мысли Чаадаева лежит, кажется, на всех философах России, тем не менее Чаадаев «не создал школы», а попытки приписать ему такую роль носят односторонний характер и в действительности лишь принижают его значение для истории русской философии.

В дополнение к тотальности и синтетичности учредительного мифа по отношению к вырастающим из него результатам мы обозначили еще одну важную особенность: сопутствующую Чаадаеву ауру тайны, загадочности, уникальности, признаки присутствия иного мира. В этом отношении личность Чаадаева представляется исключительной, оригинальной, удивительной как по характеру, так и по жизненному пути. О Чаадаеве говорят, что ему свойственны выдающиеся, поразительные способности и предрасположенность к великим делам и свершениям, но в то же время меланхолия, неприступность, холодность и отрешенность от мира, некоторая непроницаемость для окружающей среды. Религия являлась не только важным элементом его философских взглядов, но и особенностью или компонентом его личности. Сила и степень религиозности, по сути, ставят Чаадаева в оппозицию по отношению к освободительным движениям, в которых, как правило, сильны антирелигиозные настроения. Однако по отношению к традиционному в этом смысле русскому обществу это была религия совершенно отдельная, внеконфессиональная, в которой ощущалось очарование католицизмом. Впрочем, внеконфессиональность не была аморфной; так, с большой неприязнью Чаадаев относился к

\footnotetext{
${ }^{1}$ С воззрениями упомянутых авторов можно без труда ознакомится в статьях в издании: П. Я. Чаадаев: pro et contra (Прим. ред.)
} 
протестантизму. Ему было близко романтическое настроение меланхолии, но в то же время ему сопутствовали действия резкие и решительные, что привело одну из корреспонденток Чаадаева к такой примечательной оценке его личности: «уныние и нетерпение - две слабости, которым вы часто поддаетесь» (Чаадаев, 19916: 454) - слабости, обратим внимание, полностью противоположные друг другу. Религиозный пантеистический анти-индивидуализм Чаадаева соединяется в то же время с крайним, даже болезненным вниманием к автономии собственного «я», к примату «я» по отношению ко всем решениям и оценкам, сдерживающим это «я». Это делало Чаадаева и привлекательным союзником освободительных проектов, и вдохновителем усиления личностного фактора в концепциях русских религиозных философов.

До сих пор остаются неясными все обстоятельства скандала с публикацией первого философического письма, но не менее загадочны обстоятельства отказа Чаадаева от военной службы, его отношения с католицизмом, его «управление» своей личной жизнью. Холодность и отчуждение, а, с другой стороны, сильная потребность в обществе и аудитории, возможно, не без оснований приводят интерпретаторов и исследователей - невзирая на дешевую поспешность и злоупотребления такими оценками - к назначению Чаадаева на роль юродивого (Ермичев (сост.), 1998: 739).

В этой статье мы определяем жизнь и творчество Петра Чаадаева как учредительный миф русской философии. Вряд ли термин применим в отношении какого-либо другого русского мыслителя. Природа и сила чаадаевского учредительного мифа, тот факт, что в более поздний период мы имеем дело не только с конкретизацией и односторонними расширениями, но и с эффективными попытками поддержать объединяющую силу и целостность мифа, приводит к тому, что время от времени в русской философии можно усмотреть своего рода повторы, которые оживляют пути ее развития. Такого рода повторным всплеском энергии учредительного мифа будет, несомненно, творчество Владимира Соловьева, позже, возможно, - альманах «Вехи». Невзирая на то, что основное содержание обоих явлений в истории русской философии богаче - и гораздо, - они в определенном, узком смысле остаются всего лишь повторениями, вариациями прототипа - чаадаевского учредительного мифа. Под таким углом зрения даже Соловьев - лишь эпигон Чаадаева (Там же: 207). 


\section{Литература}

Герцен А. Н. (2018). Былое и думы: в 3-х томах. Т. 2. М.: Юрайт.

Гершензон М. О. (1908). П. Я. Чаадаев. Жизнь и мышление. СПб.: Типография М. М. Стасюлевича.

Евлампиев И. И. (2000). История русской метафизики в XIX-XX веках: русская философия в поисках Абсолюта. Т. 1. СПб., Алетейя.

Ермичев А. А. (ред.) (1998). П. Я. Чаадаев: pro et contra. Антология. СПб.: РХГИ.

Чаадаев П. Я. (1991а). Философические письма. Письмо первое // Чаадаев П. Я. Полное собрание сочинений и избранные письма. В 2-х т. Т. 1. М.: Наука. С. 320-339.

Чаадаев П. Я. (19916). Письмо к Ф. В. Й. Шеллингу. 1832 // Чаадаев П. Я. Полное собрание сочинений и избранные письма. В 2-х т. Т. 2. М.: Наука. С. 75-78.

Jedliński M. (2015). Rosyjskie poszukiwania sensu i celu. Bydgoszcz.

Przebinda G. (1998). Od Czaadajewa do Bierdiajewa. Spór o Boga i człowieka w myśli rosyjskiej (1832-1922). Kraków.

Walicki A. (2005). Zarys myśli rosyjskiej. Od Oświecenia do renesansu religijno-filozoficznego. Kraków. 


\section{PETR CHAADAEV AS THE CONSTITUENT MYTH OF RUSSIAN PHILOSOPHY}

\section{Janusz Dobeszewski}

Professor, Lecturer, Institute of Philosophy, University of Warsaw;

specializes in the history of philosophy, social philosophy, philosophy of religion, Russian philosophy.

Email: dobieszewski@uw.edu.pl

$\eta$

he concept of a constituent myth (aitiología) concerns the Genesis and sources of significant events and phenomena in the history of culture, civilization and social life, which are still remembered or at least do not cease to attract the attention of historians. But the term is also used to describe today's situations, almost before our eyes, if they want to give importance and depth, pointing to their origins. In the history of Russian philosophy, only Chaadaev looks in this role as effectively and convincingly as possible. The article considers the parameters proving this position.

Keywords: P. Chaadaev, constituent myth (aitiología), "Philosophical letters", Westernism, Slavophilism.

\section{References}

Chaadaev P. (1991a). Filosoficheskie pis'ma. Pis'mo pervoe [Philosophical Letters. The First Letter] Polnoe sobranie sochinenij i izbrannye pis'ma [Complete Works and Letters], 2 Vols, vol. 1, pp. 320-339, Moscow: Nauka (in Russian).

Chaadaev P. (1991b). Letter to F. W. J. von Schelling. 1832, Polnoe sobranie sochinenij i izbrannye pis'ma [Complete Works and Letters], 2 Vols, vol. 2, Moscow: Nauka, pp. 75-78 (in Russian). Gercen A. [Herzen A.] (2018). Byloe i dumy: v 3-h tomah [Past and thoughts, 3 Voks]? Vol. 2. Moscow: Yurajt (in Russian).

Gershenzon M. (1908). P. Chaadaev. ZHizn' i myshlenie [Life and thinking], Saint-Petersburg: Tipografiya M. M. Stasyulevicha (in Russian).

Ermichev A. (edit) (1998). P. Chaadaev: pro et contra. Antologiya [P. Chaadaev: Pro et Contra. Antology], Saint-Petersburg: Russian Christian Humanitarian Institute (in Russian).

Evlampiev I. I. (2000). Istoriya russkoj metafiziki v XIX-XX vekah: russkaya filosofiya v poiskah Absolyuta [Russian Russian metaphysics in the XIX-XX centuries: Russian philosophy in search of the absolute], Vol. 1. Saint-Petersburg: Aletejya, (in Russian).

Jedliński M. (2015). Rosyjskie poszukiwania sensu i celu. Bydgoszcz.

Przebinda G. (1998). Od Czaadajewa do Bierdiajewa. Spór o Boga i człowieka w myśli rosyjskiej (1832-1922). Kraków.

Walicki A. (2005). Zarys myśli rosyjskiej. Od Oświecenia do renesansu religijno-filozoficznego. Kraków. 